\title{
Multi-criteria analysis applied to railway rehabilitation
}

\author{
Vasco Caetano ${ }^{1, *}$, Paula Couto $^{2}$, Simona Fontul $^{34}$, and Maria João Falcão Silva ${ }^{2}$ \\ ${ }^{1}$ Nova University of Lisbon, Faculty of Science and Technology, Master in Civil Engineering \\ (Structures), Caparica, Portugal \\ ${ }^{2}$ National Laboratory for Civil Engineering, Department of Buildings, Assistant Researcher, Lisbon, \\ Portugal \\ ${ }^{3}$ National Laboratory for Civil Engineering, Department of Transportation, Assistant Researcher, \\ Lisbon, Portugal \\ ${ }^{4}$ Nova University of Lisbon, Faculty of Science and Technology, Department of Civil Engineering, \\ Invited Assistant Professor, Caparica, Portugal
}

\begin{abstract}
The railway infrastructure has very specific constraints that lead to the need of maximizing of the availability of infrastructure, with high levels of safety and quality, associated with an optimized cost. Having said this, it is essential to understand the methods behind the inspection and monitoring of existing railway infrastructures, the way of processing their data, as well as existing rehabilitation solutions. The present work begins with a brief description of the components of the ballast track and its operation, the different types of actions to which it is subjected to and the degradation mechanisms at the level of the ballast layer, substructure and transition zones, with particular attention being given to the latter since it is a section of the road with singularities that lead to a more pronounced degradation. The rehabilitation solutions addressed in this work start from a slight attack of the road (which can be considered as a small intervention) until a complete renovation of the road with reinforcement of the foundation. Based on the previously mentioned concepts, it is possible to define which variables, criteria and respective weights are more important and influence the investment decision (on the rehabilitation of the railway infrastructure), thus enabling the methodologies of multi-criteria analysis applied to these variables. Currently, the economic factor is one of the variables that influence the most in decision making due to the lack of investment capacity. Mainly because of this factor and sometimes even without performing an analysis, one of the common practices is the restriction of circulation velocity rather than maintenance or rehabilitation measures. The case study used is an excerpt from a railroad in Portugal, where the entire described process will be applied and consequently analysed. Therefore, this work intends to contribute to a more efficient planning of the railway maintenance and rehabilitation measures, based on a better use of the data resulting from the track inspection, through a multicriteria analysis.
\end{abstract}

\footnotetext{
* Corresponding author: v.caetano@campus.fct.unl.pt
} 


\section{Introduction}

The selection of railway line for rehabilitation represents capital investment decision making. Repair and maintenance interventions in railways are required when a given monitoring unit condition is not acceptable (out of stablished limits) for the operationality, structural stability and management strategy. Considering the financial restrictions and efficiency, as well as what is common practice, the train circulation velocity is restricted, or the interventions are frequently performed either at a reach or at a structural element level. The projects can be, namely, evaluated through one criterion, but also based on several criteria. The methods of multi-criteria decision-making (MCDM) are used when all the indicators cannot be presented through one criterion, and the weights of individual criteria are determined in different ways, and evaluated or classified within a single criterion. By these reasons, this is the focus of the present work where, using a Multi-criteria analysis (MCA) method, a score measure is obtained that allows prioritization of railway rehabilitation interventions.

\section{State of the art of MCA}

There are various decision-support techniques for assessing transport investments, such as Cost-Benefit Analysis (CBA), Cost-Effectiveness Analysis (CEA), and MCA. CBA compares costs and benefits of an alternative and uses monetary values to measure all the effects; CEA provides an assessment of the costs of alternative options which all achieve the same objective. These techniques seem to be more objective than MCA, but they don't include those effects which cannot be monetized and it can be too narrow as other impacts can have influence on the final decision making. On the other hand, the MCA simultaneously evaluates the achievement of some objectives by quantifying quantitative and qualitative, not necessarily in monetary terms. The way for measuring the criteria has somehow a subjective component, but it allows the combination of quantitative and qualitative indicators [1]. MCA has grown significantly since the 1970s and there are several types of problems that may be solved using multi-criteria techniques, classified in the following categories: i) ranking (the decision maker [DM] wants to rank the actions from the best to the worst); ii) choice (the DM wants to choose the best option among several); iii) sorting/classification (the DM wants to assign the actions to pre-defined categories). Different multi-criteria techniques exist among which the following were chosen to example: i) AHP [2]; ii) ELECTRE [3]; iii) PROMETHEE [4]; iv) Measuring Attractiveness by a Categorical based Evaluation Technique (MACBETH) [3-9].

\subsection{MACBETH technique}

The decision problem emerges when the DM searches for the most desirable action (decision, alternative, variant) among many feasible actions (decisions, alternatives, variants). The transportation decision problem results from the DM's observations of the "transportation" reality and the recognition of such a problem or situation that needs to be solved or requires the decision to be made. The analyst constructs the decision models (multiobjective ranking problem) and suggests certain decision tools to solve the problems [10]. MACBETH has been used successfully in a very large sphere of different fields. Ordinal measurement of the attractiveness is part of the process needed to obtain cardinal information. Ordinal information is related to ordering of alternatives using ordinal numbers and cardinal with a more quantitative approach [5]. The MACBETH process is organized in stages, including definition of value tree, criteria, performance levels and scale 
of weights. Using the table of performances and the weights, it is possible to compute the scores of each alternative that allows establishing a rank.

A further step in the evolution of appraisal methods is the explicit introduction of a stakeholder notion in the analysis. A stakeholder is by definition any individual or group of individuals that have an interest (financial or otherwise), in the consequences of any decisions taken and can influence or are influenced by the achievement of the organisation's objectives. An in-depth understanding of each stakeholder group's objectives is critical in order to appropriately assess the different alternatives [11].

\subsection{Methods and applications}

At least seven types of MCDM applications can be identified in general infrastructure management [12] (see Fig. 1): i) Water resources systems (water resources such as river basin, watershed and dams); ii) Water and wastewater mains (management of drinking or fresh water, wastewater or sewerage distribution); iii) Transportation concerning with roads, pavement, highways, rail and transit; iv) Bridges (design, construction, maintenance, assessment and management); v) Buildings (problems of structures such as high-rise building and multi-housing projects); vi) Underground infrastructure (manage underground infrastructure such as gas, petroleum pipelines, tunnels and subway); vii) Others dealing with applications in urban infrastructure, urban drainage systems, offshore refinery plants, critical infrastructure, etc.

\begin{tabular}{|c|c|c|c|c|c|c|c|c|c|}
\hline Application area & WSM & AHP & ELECTRE & PROMETHEE & $\mathrm{CP}$ & TOPSIS & VIKOR & $\begin{array}{l}\text { Combined } \\
\text { methods }\end{array}$ & Total \\
\hline Water resources systems & 3 & 5 & 3 & 9 & 8 & 1 & 3 & 36 & 68 \\
\hline Water and wastewater main & 2 & 15 & 8 & 7 & 4 & 1 & 1 & 15 & 53 \\
\hline Transportation & 2 & 30 & 5 & 1 & 0 & 4 & 0 & 14 & 56 \\
\hline Bridges & 0 & 7 & 0 & 0 & 0 & 0 & 0 & 51 & 58 \\
\hline Buildings & 1 & 5 & 2 & 1 & 1 & 5 & 2 & 16 & 33 \\
\hline Underground infrastructure & 1 & 4 & 1 & 1 & 1 & 0 & 0 & 3 & 11 \\
\hline Others & 1 & 6 & 0 & 0 & 0 & 5 & 0 & 9 & 21 \\
\hline Total & 10 & 72 & 19 & 19 & 14 & 16 & 6 & 144 & 330 \\
\hline
\end{tabular}

Figure 1 - Distribution of MCDM papers by methods and applications [12].

The total number of papers that utilised one of the MCDM methods increased from single digit numbers in early 1980s to hundreds towards the late 2000s (see Fig. 2). Nevertheless, the fraction of MCDM papers within infrastructure papers (including transportation) is steadily growing [12].

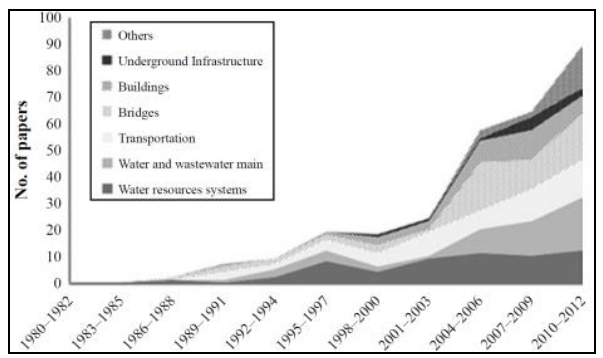

Figure 2 - Distribution and growth of MCDM papers by methods between 1980 and 2012 [12].

The application of multi-criteria analysis in the transport sector has a very broad scope [11], ranging from: the evaluation of policy measures in passenger transport [13], to strategic decisions [11,14], technologies [15,16], locations $[17,18]$, and finally infrastructure projects [19]. Considering the different type of infrastructures, it is mainly 
applied to roads. In Table 1 is a brief review of MCA techniques applications on railway infrastructures.

Table 1. MCA techniques applications on railway infrastructures.

\begin{tabular}{ccc}
\hline Subject studied & MCA technique adopted & References \\
\hline $\begin{array}{c}\text { Analysis of the railway service quality and traffic safety } \\
\text { risk }\end{array}$ & $\begin{array}{c}\text { WSA, AHP, TOPSIS, DEA, } \\
\text { VIKOR }\end{array}$ & {$[20-33]$} \\
\hline Planning and designing of railways & $\begin{array}{c}\text { WSM, AHP, ELECTRE, } \\
\text { MAMCA, MACBETH, COSIMA } \\
\text { and VIKOR }\end{array}$ & {$[34-40]$} \\
\hline Selection of maintenance actions & AHP, ANP & {$[41-45]$} \\
\hline Supplier selection in railway projects & Mixed & {$[46]$} \\
\hline Risk analysis of general accidents & AHP & {$[47]$} \\
\hline Design scheme selection of railway freight car & AHP & {$[49]$} \\
\hline Selection of manufacturer of rail vehicles & AHP & {$[50]$} \\
\hline Selection of equipment for railway crossing at stations & AHP & {$[51]$} \\
\hline
\end{tabular}

After analysing the above sources, it can be stressed that the AHP method is the mostly used MCA method for solving railway infrastructural problems. Note that AHP method has some similarities with the MACBETH. Other conclusion is that the repair, maintenance and rehabilitation field has scarce studies with MCA collaboration.

\section{Case Study set up}

The aim of this work (in progress) is to implement the MACBETH methodology in order to assess the feasibility of a sustainable railway rehabilitation solution for a given case.

\subsection{Railway rehabilitation importance}

Concerning Railways, track maintenance means the total process of maintenance and renewal required to ensure that the track meets safety and quality standards. Ideally, this goal should be achieved at minimum cost [52]. Profillidis [53] argues that "with respect to safety, maintenance should be preventive; regarding comfort, maintenance should be corrective; and finally, as regards the economic aspects of maintenance, an optimum solution should be sought, so as to ensure a satisfactory safety margin and prevent a quick degradation of track quality". However, the objective of inspection is not only to assure the non-existence of any faults that might lead to accidents, but also to monitor successive degradation in infrastructure in order to prevent faults and to provide the infrastructure manager with information for short and long term planning of maintenance activities [54].

\subsection{Main actors and criteria to be considered}

Including stakeholder groups in the decision-making process is, certainly in the transport sector, a crucial element in the successful implementation of the measure. Citizens, government, investors/operators, private companies and different policy levels will have a large impact on the implementation of a project [55]. For the transport sector, many different stakeholders are often involved like managers, customers of the transportation companies, owners and managers of the companies, employees of the companies (drivers, for example), authorities responsible for transport operations, local communities, building maintenance and repair organisations, self-governance institutions, producers and suppliers of materials and products, designers, contractors, etc [8,28,29]. 
In the field of railway rehabilitation, there are different families of criteria (and subcriteria) to be considered like financial, economic and environmental. In this context, the following goals have been defined: minimize the operating and maintenance costs, minimize the timespan intervention, maximize the benefit for railway line users (service quality, traffic safety), minimize the effects on location development, and minimize the effect on the environment. Note that the environmental impact analysis takes into account any possible changes, negative or positive, on the biological, physico-chemical and socioeconomic aspects of the environment that may arise from the missing or implementation of the rehabilitation solution [34]. Other important aspect is that the opinion of users has to be taken into account due to service quality (duration of transportation, comfort, safety and others) in order to maintain the competitiveness with other transportation facilities.

\subsection{Rehabilitation solutions to be studied}

In the present work will be considered five different rehabilitation solutions, such as, slight attack of the road, re-ballasting, reinforcement with geosynthetics, foundation strengthening, and integral renewal of the road with reinforcement of the foundation.

\section{Final considerations}

It is important to ensure that any infrastructure investment will have (essentially) beneficial effects on the overall transport system and those affected by it. Therefore, it is very likely that this MCA method will be a wise choice since it is intended to incorporate both quantitative and qualitative indicators when studying the feasibility of a sustainable railway rehabilitation solution for a given case.

\section{References}

[1] J.S. Dodgson, M. Spackman, A. Pearman, and L.D. Phillips, Department for Communities and Local Government: London, (2009).

[2] T.L. Saaty, International Journal of Services Sciences, 1, 83-98 (2008).

[3] M. Rogers, M. Bruen, and L.-Y. Maystre, "ELECTRE and Decision Support", Springer US, Boston, MA (2000).

[4] J. Brans, Faculte Des Sciences de l'Administration, Universite Laval, (1982).

[5] C.A. Bana E Costa, J.-M. De Corte, and J.-C. Vansnick, International Journal of Information Technology \& Decision Making, 11, 359-387 (2012).

[6] C. Bana e Costa, J.-M. De Corte, and J.-C. Vansnick, "MACBETH. (Overview of MACBETH multicriteria decision analysis approach)", (2003).

[7] C.A. Bana e Costa, J.-M. de Corte, J.-C. Vansnick, J.J. Cochran, L.A. Cox, P. Keskinocak, J.P. Kharoufeh, and J.C. Smith, MACBETH (Measuring Attractiveness by a Categorical Based Evaluation Technique), in: Wiley Encyclopedia of Operations Research and Management Science, John Wiley \& Sons, Inc., (2010).

[8] C.A. Bana e Costa, J.-M. De Corte, and J.-C. Vansnick, Www.M-MACBETH.Com, (2017).

[9] C.A.B. e Costa and J.-C. Vansnick, General Overview of the Macbeth Approach, in: Advances in Multicriteria Analysis, Springer, Boston, MA, (1995), pp. 93-100.

[10] J. Zak, The MCDA methodology applied to solve complex transportation decision problems, in: (2002).

[11] M. Dooms and C. Macharis, Institutional Aspects in Transport Project Evaluation, (2006).

[12] G. Kabir, R. Sadiq, and S. Tesfamariam, Structure and Infrastructure Engineering, 10, 1176-1210 (2014).

[13] M.E. Bouwman and H.C. Moll, Transportation Research Part D: Transport and Environment, 7, 331-345 (2002).

[14] R. Vreeker, P. Nijkamp, and C. Ter Welle, Transportation Research Part D: Transport and Environment, 7, 27-47 (2002).

[15] C. Macharis, A. Verbeke, and K. De Brucker, Research in Transportation Economics, 8, 443-462 (2004).

[16] G.-H. Tzeng, C.-W. Lin, and S. Opricovic, Energy Policy, 33, 1373-1383 (2005). 
[17] C. Macharis, (2000).

[18] A. Sirikijpanichkul and L. Ferreira, (2005).

[19] K. De Brucker, "Sociaal-economische evaluatie van overheidsinvesteringen in transportinfrastructuur: kritische analyse van het bestaande instrumentarium Ontwikkeling van een eclectisch evaluatie-instrument", Garant, (1998).

[20] L. Eboli and G. Mazzulla, "A multicriteria approach for analyzing railway service quality", (2013).

[21] L. Maskeliunaite and H. Sivilevicius, Applying AHP technique to the assessment of railway trip quality (RTQ), in: (2011).

[22] E. Nathanail, Transportation Research Part A: Policy and Practice, 42, 48-66 (2008).

[23] G. Bureika, L. Liudvinavičius, G. Vaičiūnas, and G. Bekintis, Eksploatacja i Niezawodność, 15, (2013).

[24] H. Gerçek, B. Karpak, and T. Kılınçaslan, Transportation, 31, 203-228 (2004).

[25] H. Sivilevičius and L. Maskeliūnaite, Transport, 25, 368-381 (2010).

[26] L. Maskeliūnaite, H. Sivilevičius, and V. Podvezko, Transport, 24, 100-112 (2009).

[27] M. An, Y. Chen, and C.J. Baker, Information Sciences, 181, 3946-3966 (2011).

[28] S. Chen, Y. Leng, B. Mao, and S. Liu, Transportation Research Part A: Policy and Practice, 66, 13-26 (2014).

[29] N. Aydin, Transport Policy, 55, 87-98 (2017).

[30] M.K. Sameni, J. Preston, and M.K. Sameni, Research in Transportation Business \& Management, 20, 33-38 (2016).

[31] E. Celik, N. Aydin, and A.T. Gumus, Transport Policy, 36, 283-293 (2014).

[32] F. Yong, Q. Yong, Z. Shuting, L. Wantong, J. Limin, L. Xinwang, Z. Zhilong, and L. Jianying, Operation safety assessment of high-speed train with fuzzy group decision making method and empirical research, in: IEEE, (2016), pp. $35-42$.

[33] G. Longo, G. Medeossi, and E. Padoano, Using simulation to assess infrastructure performance in multicriteria evaluation of railway projects, in: (2012).

[34] I.Z. Nedevska, Z.M. Krakutovski, and Z.S. Zafirovski, Tehnika, 72, 797-805 (2017).

[35] L. Markovic, D. Marković, and G. Ćirović, APPLICATION OF MULTICRITERIA OPTIMIZATION IN DESIGNING RAILWAY LINE AT THE LEVEL OF THE MAIN PROJECT, in: (2012).

[36] M. De Luca, G. Dell'Acqua, and R. Lamberti, Procedia-Social and Behavioral Sciences, 54, 608-617 (2012).

[37] I. Ambrasaite, M.B. Barfod, and K.B. Salling, Procedia-Social and Behavioral Sciences, 20, 944-953 (2011).

[38] M.R. Saat and J. Aguilar Serrano, Transportation Planning and Technology, 38, 200-213 (2015).

[39] M. Kosijer, M. Ivic, M. Markovic, and I. Belosevic, Gradevinar, 64, 195-205 (2012).

[40] R. Mateus, J.A. Ferreira, and J. Carreira, European Journal of Operational Research, 187, 1-18 (2008).

[41] B. Nyström and P. Söderholm, Structure and Infrastructure Engineering, 6, 467-479 (2010).

[42] N.F. Tamirat, Ethiopian E-Journal for Research and Innovation Foresight (Ee-JRIF), 6, (2014).

[43] J. Montesinos-Valera, P. Aragonés-Beltrán, and J.-P. Pastor-Ferrando, Structure and Infrastructure Engineering, 13, 1476-1496 (2017).

[44] S. Filippo, P.C.M. Ribeiro, and S.K. Ribeiro, Transportation Research Part D: Transport and Environment, 12, 423-436 (2007).

[45] D. Moazami, H. Behbahani, and R. Muniandy, Expert Systems with Applications, 38, 12869-12879 (2011).

[46] R. Janssen, Journal of Multi-Criteria Decision Analysis, 10, 101-109 (2001).

[47] G. Polat and E. Eray, Procedia Engineering, 123, 415-422 (2015).

[48] P. Jiang, D. Wang, and Y. Xing, Risk Analysis of General Accidents in China Railway Passenger Transportation, in: IEEE, (2015), pp. 950-953.

[49] Y.-H. Li, Design scheme selection of railway freight car using a fuzzy analytic hierarchy process, in: IEEE, (2009), pp. 267-271.

[50] S. Dhir, M.V. Marinov, and D. Worsley, Case Studies on Transport Policy, 3, 431-448 (2015).

[51] J. Čaiko, N. Kuṇicina, A. Pațins, A. Pelṇik̦is, and L. Ribickis, Publication. EditionName, 151-154 (2008).

[52] C. Esveld, "Modern railway track", 2. ed, MRT-Productions, Zaltbommel (2001).

[53] V. Profillidis, "Railway management and engineering", Routledge, (2016).

[54] M. Andersson, TRITA-INFRA, (2002).

[55] W.E. Walker, Journal of Multicriteria Decision Analysis, 9, 11 (2000).

[56] E.K. Zavadskas, J. Antuchevičienè, and O. Kapliński, Engineering Structures and Technologies, 7, 103-113 (2015).

[57] J. Zak and T. Thiel, Multiple criteria evaluation of the development scenarios of the mass transit system, in: (2001). 